\title{
Effects of Separate and Combined Chronic Ingestion of Codeine and Tramadol on Exploratory Learning Behaviour Among Male Albino Rats
}

\author{
Shyngle Kolawole Balogun ${ }^{1,}$, , Jackson Iheukwumere Osuh ${ }^{2}$, Oluwatosi Olatunde Olotu ${ }^{1}$ \\ ${ }^{1}$ Department of Psychology, Faculty of the Social Sciences, University of Ibadan, Ibadan, Nigeria \\ ${ }^{2}$ Department of Psychology, Faculty of Social Sciences, Federal University, Oye-Ekiti, Nigeria
}

Email address:

shyngle61@yahoo.com (S. K. Balogun)

${ }^{*}$ Corresponding author

To cite this article:

Shyngle Kolawole Balogun, Jackson Iheukwumere. Osuh, Oluwatosi Olatunde Olotu. Effects of Separate and Combined Chronic Ingestion of Codeine and Tramadol on Exploratory Learning Behaviour Among Male Albino Rats. American Journal of Applied Psychology. Vol. 9, No. 4, 2020, pp. 99-107. doi: 10.11648/j.ajap.20200904.13

Received: June 24, 2020; Accepted: July 9, 2020; Published: July 17, 2020

\begin{abstract}
Tramadol and codeine are opioids known to have effective analgesic effects and potentials for the possible development of tolerance and addiction. The recent increase in the use and abuse of these substances coupled with research evidence implicating the ability of these opioids to readily access opioid receptors in the central nervous system (CNS) is a source of research concern. This study, therefore, examined the effects of chronic exposure to codeine and tramadol on exploratory learning behaviour. Twenty-four (24) male albino rats weighing between 150-200g and 4-6 weeks old, collected from the University of Ibadan Veterinary animal farm were used for this study. They were divided into 4 experimental groups of codeine, tramadol, combined codeine and tramadol and control groups with 6 rats in each group. They were exposed to $8 \mathrm{mg} / \mathrm{kg}$ of codeine, $20 \mathrm{mg} / \mathrm{kg}$ of tramadol, combined $8 \mathrm{mg} / \mathrm{kg}$ of codeine and $20 \mathrm{mg} / \mathrm{kg}$ of tramadol, and normal saline for the codeine, tramadol, combined codeine and tramadol and control groups respectively for 28 days. The rats were administered with the drugs every other day and observed after each treatment day for exploratory learning behaviour using the T-maze. randomized block ANOVA showed a significant effect of codeine and tramadol on exploratory learning behaviour among male albino rats, $f(3,67)=19.08, p<0.001, \eta 2=.08$. Male albino rats in the codeine treatment group significantly took more time exploring the maze $($ Mean $=176.64)$ than combined group $($ Mean $=168.13)$, tramadol group (Mean =131.10) and control group (Mean $=92.48)$. The mean differences were significant $(\mathrm{p}<.001)$. It was concluded that chronic exposure to tramadol and codeine has implications for exploratory learning and memory deficits.
\end{abstract}

Keywords: Exploratory Learning Behavior, Codeine, Tramadol, Male Albino Rats

\section{Introduction}

Drug use, abuse and dependence and its consequences have been a major concern for many nations. A report of the United Nations Office on drugs and crime, recorded in World Drugs Report in 2017, indicate that around a quarter of a billion people used drugs, and approximately 29.5 million showed drug use disorders, including dependence [1].

The reasons why humans indulge in drug use and abuse are usually varied and they include reducing anxiety, obtaining pleasurable feelings, relieving pain or stress, increasing energy, and enhancing sociability. Drug abuse and addiction leading to harm to the individual and the society at large, does not constitute the use of drugs for the reasons listed above, but rather the chronic, uncontrolled use of drugs at the expense of normal activities and despite adverse consequences that characterize drug addiction. Getting addicted to drugs takes a process which may span over the years to develop and can be likened to a learning process. Learning to depend on a drug begins when the individual perceives that taking a particular drug is rewarding with an increasing desire to use the drug again. Environmental cues may be associated with the drug intake overtime which may alone be sufficient to stimulate the desire or craving for the 
drug. Drugs of abuse taken over time can affect the functions of the neural systems mediating self-control over behaviour and making them to dysfunction. Some research reports indicate that addictive drugs can affect normal learning systems as well as inhibit the ability to control the use of the drugs, particularly in vulnerable populations like adolescents $[2,3]$. Some of such drugs are the opioids which include tramadol and codeine.

Tramadol is a synthetic opioid and centrally acting analgesic. It is a serotonin/norepinephrine reuptake inhibitor (SNRI) that is structurally related to codeine and morphine. Tramadol is considered a low-risk opioid for the treatment of moderate to severe pain because it is considered tolerable as an analgesic and has a multimodal mechanism of action. [4]. It can stimulate the mu-opioid receptors or inhibit the serotonin and norepinephrine reuptake which explains why it has antidepressant effects [5]. Tramadol is a racemic compound that has two enantiomers with two distinct and complementary mechanisms of action. They are the $(+)$ tramadol which is a selective agonist of mu-opioid receptor and which preferentially inhibits serotonin reuptake and enhances serotonin release in the brain, and the (-) enantiomer which mainly inhibits noradrenaline reuptake [6]. The major metabolite of both enantiomers of tramadol is O-desmethylTramadol which is known to be more potent in the stimulation of mu-opioid receptor than the parent compound [7].

Because tramadol is considered a low opioid analgesic, it is used chronically to treat morphine and other opioids withdrawal syndrome [8]. Tramadol is usually prone to abuse particularly by adolescents and young adults because of its mixed and specific mechanism of action [9]. There are indications that the use and abuse of tramadol, either for clinical purposes or for abuse is on the increase in recent times [10]. The 39th WHO, ECDD Report [11], indicated a widespread misconception regarding the use of tramadol among the general population with some viewing it as a mood enhancer, means to increase sexual stamina or as an energy booster during work. Individuals who abuse tramadol report that such mood-elevating properties cause them to take higher doses of the drug or to take it more often than had been prescribed leading to abuse of tramadol, causing psychological or physical dependence and increasing the potential for overdose risks.

Codeine is an opiate drug which is readily available and used worldwide. It is commonly used for analgesic, antitussive and antidiarrheal purposes. [12]. Codeine is viewed as a weak opiate although it has the potential for misuse, abuse and possible dependence. Side effects associated with the use and abuse of codeine include sedation, euphoria and constipation (12). Prolonged use of codeine may lead to possible physical tolerance and dependence, and stoppage of use can result in unpleasant withdrawal symptoms which may include physical effects [13]. Codeine is usually available in many countries of the world as overthe-counter (OTC) preparations although it is still a prescription drug for the management of moderate pain. The ready availability of codeine creates an impression of its potential for habit-forming use, risk of development of tolerance and dependence with related health harms particularly relating to excessive or long-term use $[14,15]$.

Opiate abuse occurs when codeine-containing products are used for recreational and excessive dose purposes as opposed to medical purposes [16]. Codeine and codeine-containing products are among the drugs of abuse majorly by youths and young adolescents which has become a foremost emerging health challenge in various nations around the world. This might be attributed to the fact that the drugs are accessible in the range of over-the-counter (OTC) medications which are constantly bought without the need of a doctor's prescription [17]. According to a documentary titled "Sweet Sweet Codeine" released by British Broadcasting Corporation (BBC) in May 2018, thousands of youths in Nigeria, for instance, are addicted to codeine-containing products, especially the cough syrup formulation. This, however, led to the subsequent ban on the importation and sale of codeine as an active pharmaceutical ingredient (API) by the National Agency for Food and Drug Administration and Control (NAFDAC) in Nigeria [18]. The ban on the importation and sale of codeine as an API has led to a drastic scarcity of codeine-containing products within the country, although, there is presently no legal backing on obtaining these products as prescription-only medicine. There are enough evidences to suggest that youths, especially students in secondary schools and tertiary institutions use drugs in order to enhance/or cope with learning and/or during examinations. It is believed that these drugs help in facilitating their assimilation and retention of learned items,

Some studies have tried to explain the relationship between the influence of psychoactive drug use on learning and memory. There is shared neurobiological mechanisms involved in learning and memory processes and the druginduced structural and functional changes in the brain [19]. According to [19] an important overlap between the neural substrates of learning and memory and those of addiction exist. Some of the areas of overlap include the cerebral cortex, hippocampus, amygdala and striatum which are all components of the mesolimbic dopaminergic system.

Drugs of abuse are known to have direct pharmacological actions on multiple neurotransmitter systems which enables them to have the ability to usurp normal learning and memory systems. Therefore, they mimic the dopamine signal generation in the midbrain to both the dorsal and ventral striatum which facilitate the learning of new events in the environment $[20,21]$. The outcome is that the drugs which are mostly addictive substances create artificial learning signals that are of a greater magnitude and duration than what is observed neuro-chemically in response to the natural.

Drugs of abuse also directly affect learning and memory processes by the alteration of normal glutamate transmission [22]. According to [23], long-lasting alterations in glutamate homeostasis in the nucleus accumbens, as well as enhanced glutamatergic transmission from the prefrontal cortex upon reexposure to the drug, are outcomes of chronic drug exposure. Glutamatergic activity is also necessary for virtually all forms 
of learning and is critical for prefrontal cortical control over decision making and impulsivity [24]. Therefore, addictive drugs can profoundly influence learning and memory circuits.

Memory formation is a complex process that requires distinct neuronal networks and multiple pre- and postsynaptic events. Studies conducted to investigate molecular mechanisms underlying activity-dependent synaptic changes during memory formation show that different neurotransmitter in the central nervous system (CNS) plays a key role in learning and memory [25]. The memory could be impaired by the stimulation of gamma-aminobutyric acid (GABA) receptor or the increase of GABA release [26, 27]. Several studies have also shown that serotonergic neurons play a significant role in the learning and memory processes $[28,29]$. Evidence in research findings indicates that the activation of opioid receptor in humans or animals impairs memory [30, 31]. Conversely, it has been shown that some antidepressants which increase the synaptic dopamine, norepinephrine and serotonin inverted the depression memory impairment $[32,29]$. The activation of mu receptors either directly or indirectly by chronic or acute use of opioid agonist could impair memory [30, 33].

Although there are some studies on the effect of acute tramadol and other opioids on memory [34, 35, 36], researches are, however, scarce on the effect of combined chronic administration of tramadol and Codeine on memory (Exploratory learning behaviour). Therefore, this study was designed mainly to experimentally examine the effects of separate and combined chronic administration of tramadol and codeine on exploratory learning behaviour of male albino rats. This orientation was based on the fact that youths now experiment with a cocktail/combination of drugs. It's as if one drug is no more enough to satiate their cravings. This study will specifically;

a) examine the effects of chronic Tramadol administration on exploratory learning behaviour among male albino rats.

b) examine the effects of chronic Codeine administration on exploratory learning behaviour among male albino rats.

c) examine the effects of combined acute administration of both Tramadol and Codeine on exploratory learning behaviour among male albino rats.

Rats were used because of their closeness to humans on phylogenetic scale and because of ethical considerations in the use of human beings in this kind of study. The following hypotheses were tested in determining the relationship between chronic administration of drugs (tramadol and codeine) on exploratory learning behaviour in male albino rats;

1. Chronic exposure to Tramadol and Codeine will significantly affect exploratory learning behaviour of male albino rats exposed to the drugs.

2. Tramadol and Codeine will singly and jointly interact to affect exploratory learning behaviour of male albino rats exposed to chronic administration of the drugs.

3. Male Albino rats exposed to chronic combined treatment of codeine and tramadol will be slower in exploratory learning than male albino rats exposed to a single exposure to codeine or tramadol

\section{Methodology}

The methodology adopted for this study which includes research design, participants, setting, instruments used, procedure and method of statistical analysis is presented.

\subsection{Research Design}

The independent group randomized design was used in this study. Participants in the study were selected and placed in four different groups. The first group was administered Codeine, the second was administered Tramadol, the third group was administered both drugs, Tramadol and Codeine and the fourth group was administered normal saline as the control group. The independent variables are the chronic administration of Tramadol and Codeine, and the combination of both drugs to the male albino rats. The dependent variable was exploratory learning behaviour displayed or exhibited by the male albino rats.

\subsection{Setting}

The experiment took place at the Animal Science Laboratory, University of Ibadan, Oyo State, Nigeria.

\subsection{Animal Population}

The animals used were male Albino rats. A total of 24 male Albino rats weighing between $150-200 \mathrm{~g}$ and $4-6$ weeks old were used. They were divided into four (4) groups with six (6) male rats in each group. The groups were Tramadol group, Codeine group, combined Tramadol and Codeine group and control group. The rats were randomly assigned to different groups.

\subsection{Drugs}

The drugs used for this study were Tramadol HCL (50 mg capsules) and Cough syrup (containing 220mg codeine). Tramadol and Codeine were administered orally with the use of an oral cannula. The rats were given $20 \mathrm{mg} / \mathrm{kg}$ bodyweight of Tramadol following the recommended $5 \mathrm{mg} / \mathrm{kg}-20 \mathrm{mg} / \mathrm{kg}$ dose for oral administration of tramadol in rats [37], while Codeine was administered at a dose of $8 \mathrm{mg} / \mathrm{kg}$ body weight every 24 hours following the recommended therapeutic dose of $2 \mathrm{mg} / \mathrm{kg} / 6 \mathrm{hrs}$ [38]. The dosage administered in this study was, therefore, Tramadol- $20 \mathrm{mg} / \mathrm{kg}$ and Codeine- $8 \mathrm{mg} / \mathrm{kg}$.

\subsection{Materials/Instruments}

The following materials and instruments were used for this study;

1. 6 experimental rat cages.

2. Recording sheets

3. Distilled water/saline

4. Laboratory coat

5. Oral cannula for the administration of drugs

6. Hand Gloves.

7. Face/Nose Mask

8. Coloured markers for easy identification of female albino rats from, the control and experimental rat. 
9. Measuring cylinders used in diluting and measuring the solution.

10. Weighing balance for the daily weighing of rats.

11. Stopwatch for timekeeping and recording

12. Disposable syringes

13. Mouse cubes for feeding the rat

14. Codeine syrup

15. Tramadol capsules (powder in capsule serially diluted with distilled water)

16. T-MAZE

\subsection{Procedure}

Before the commencement of experiments, the rats were brought into the laboratory and left to acclimatize in the laboratory for 21 days. During this period, the rats were allowed free access to food and water without any form of deprivation under the normal day-night 24-hour cycle. The rats were then randomly assigned into 4 groups; the tramadol group, the codeine group, the Combined group and the Control group with 6 male rats in each group. Each cage was clearly labelled with the drug category. Rats were also marked for identification and the rats in each cage according to their groups were labelled 1 to 6 .

The experiment started with the training of the rats on the exploratory learning process using the T-Maze for 3 days before exposing them to drug treatment. The rats were deprived of food for 24 hours to make them sufficiently hungry because the food was used as the motivation for learning in this study. During each experimental period, a male rat was put in the starting point of the T-Maze and allowed 5 minutes to explore the maze to locate the food placed in one of the arms of the maze. The time taken by each rat to locate the food within the 5 minutes' interval was recorded for each rat using the stop clock. A rat is scored zero if it was not able to locate the food in the arm within the 5 minutes allotted time. Each rat was given 3 trials during each experimental period. Food was restored to the rats at the end of each experimental period.

On each day of the experiment, all the rats were weighed and records of the weights against each rat were recorded. This was to determine what dose of drugs to administer to each rat. The drugs were then administered to each experimental group of the rats according to their body weights. The control group was given normal saline. After the drug administration, the rats were allowed 30 minutes before the commencement of data collection to give enough time for the onset of drug action. They were then run on the T-Maze to measure exploratory learning behaviour. The process of treatment and data collection was repeated every day for 28 days.

At the end of the experiment, all the rats were discarded following the procedures recommended for disposal of animals used for research purposes by the cruelty to animal act.

Statistical analysis

All results were analyzed using one-way ANOVA. Any P value less than 0.05 was considered

\section{Results}

The results of the study on the effect of chronic administration of tramadol and codeine on the exploratory learning behaviour of male Albino rats are presented. The data collected were subjected to Randomized Block Analysis of Variance (ANOVA), descriptive statistics of mean and standard deviation as well as a graphical representation.

Table 1. Summary of Factorial ANOVA table showing the influence exposure to Chronic intake of Codeine \& Tramadol on exploratory learning behaviour.

\begin{tabular}{llllll}
\hline Source & Type III Sum of Squares & Df & Mean Square & F & Sig. \\
\hline Block & 10486.276 & 1 & 10486.276 & .802 & .371 \\
Treatment & 748225.726 & 3 & 249408.575 & .001 & .000 \\
Error & 8720923.331 & 667 & 13074.848 & & \\
Corrected Total & 9479635.333 & 671 & & & \\
\hline
\end{tabular}

The result from Table 1, shows that exposure to Codeine and Tramadol significantly influenced exploratory learning behaviour among Wister Albino Rats F $(3,67)=19.08, p<$ $0.001, \eta^{2}=.08$. The result showed that tramadol and codeine interacted singly and jointly to affect exploratory learning behaviour in male Wister Albino rats.

Table 2. Summary Bonferonni mean comparison analysis showing the mean difference in exploratory learning behavior between rats exposed to chronic intake of psychoactive drugs (Codeine \& Tramadol) and those exposed to Normal saline.

\begin{tabular}{lllllll}
\hline & Mean & S.E.M & $\mathbf{1}$ & $\mathbf{2}$ & $\mathbf{3}$ & $\mathbf{4}$ \\
\hline CODEINE & 176.64 & 8.822 & - & 8.51 & $84.16^{*}$ & $45.54^{*}$ \\
COMBINED & 168.13 & 8.822 & & - & $75.65^{*}$ & $37.03^{*}$ \\
CONTROL & 92.48 & 8.822 & & & - & $38.62^{*}$ \\
TRAMADOL & 131.10 & 8.822 & & & & - \\
\hline
\end{tabular}

*. The mean difference is significant at the .05 level.

b. Adjustment for multiple comparisons: Bonferroni.
Further analysis was carried out to determine the mean differences among the treatment groups using Bonferroni mean comparison Test and the result is presented in Table 2.

From the analysis, mean differences showed that rats exposed to the combination of Codeine and Tramadol $(\bar{x}=168.13)$, Tramadol only $(\bar{x}=131.10)$ and Codeine only $(\bar{x}=176.64)$ significantly took more time learning the maze compared to rats in the control group $(\bar{x}=92.48)$. The mean differences were significant $(p<.001)$. The result demonstrated that learning time rate increased by $8 \%$ with exposure to chronic intake of Codeine and Tramadol compared to the control group. The result demonstrated that exploratory learning behaviour was poorer for rats exposed to codeine and tramadol. Male Albino rats exposed to codeine took more time in learning the maze than male Albino rats exposed to tramadol and control. 


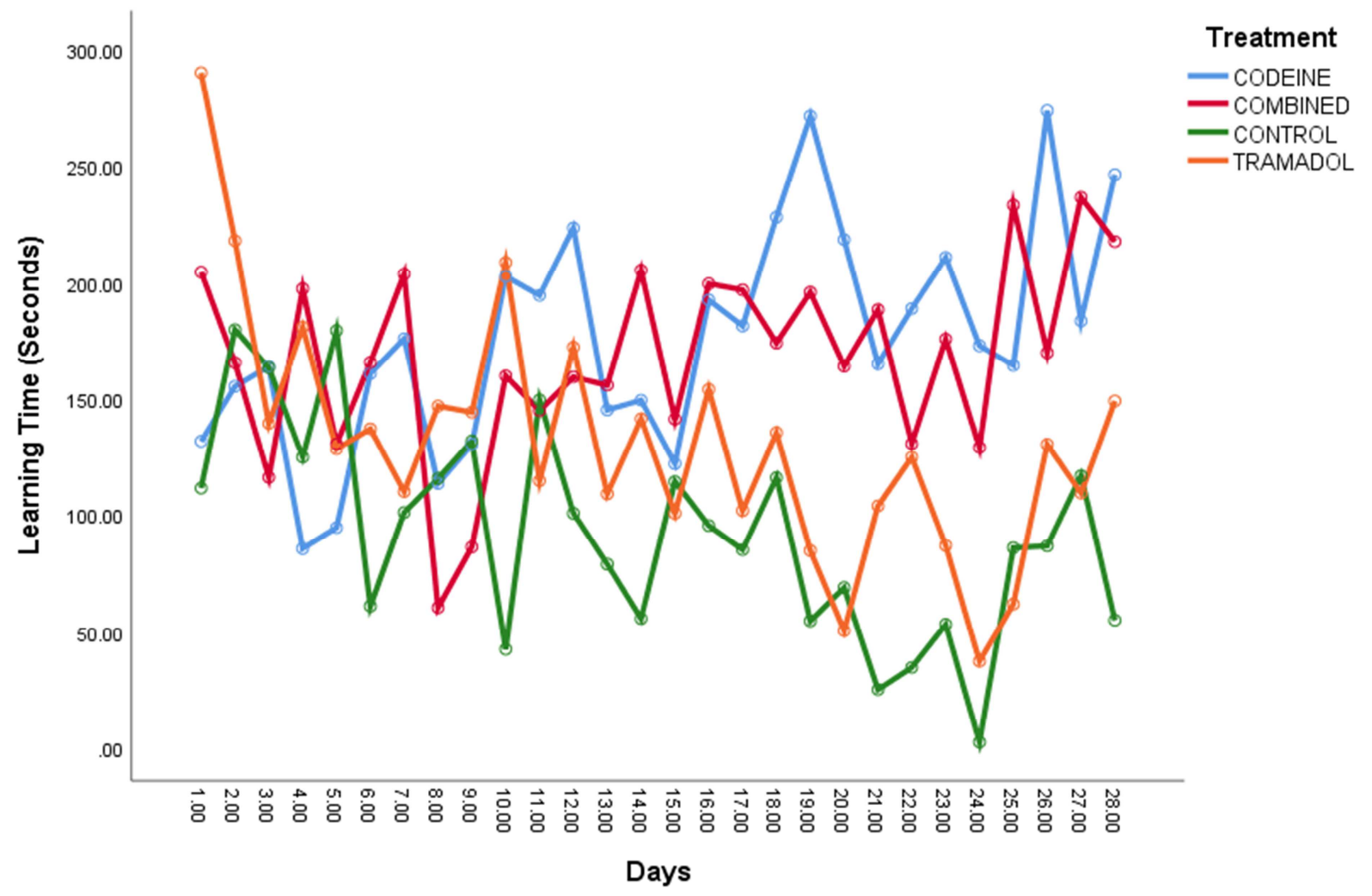

Figure 1. Interaction graph showing the interaction between time of exposure and treatment on exploratory learning behaviour with the chronic intake of psychoactive drugs (Codeine and Tramadol) among male Wister Albino rats.

The line graph shows that the longer the period of exposure to chronic intake of Codeine and Tramadol, the more it affects learning behaviour in exposed male rats.

\section{Discussion}

This study examined the chronic single and combined administration of tramadol and codeine on exploratory learning behaviour using male Albino rats. Tramadol and codeine are opioid analgesic drugs that are readily available and freely used and abused for various purposes in a wide range of people particularly adolescents and young adults. Tramadol is an opioid analgesic drug which has a different mechanism of action [10,9], and can be used for different disorders in single or multiple doses $[6,7,39]$. Tramadol can potentially show behavioural changes because it can easily cross the blood-brain barrier to reach a high level in the brain [40]. Codeine, on the other hand, is an opiate drug which is readily available and used worldwide. It is commonly used for analgesic, antitussive and antidiarrheal purposes. [12]. Codeine is viewed as a weak opiate although it has the potential for misuse, abuse and possible dependence. Morphine is a major metabolite of codeine, therefore, it extremely mimics the effects of Morphine [41]. Codeine binds with stereospecific receptors at many sites within the Central Nervous System (CNS) to alter processes affecting both the perception of pain and the emotional response to pain. Researches have shown that the ability of codeine to provide measurable pain relief requires efficient brain uptake, which is accomplished by passive diffusion enabling it to also cross the blood-brain barrier $[42,43]$.

Studies on humans and animals have indicated that morphine and other opioids can positively or negatively control learning and memory processes [44, 45]. The direction of control may be due to several factors which may include; experimental conditions used, protocols, species used, dosage applied, route of administration, and in particular the duration of the drug administration [46]. There are some studies on the effect of acute tramadol and other opioids on memory $[34,36]$, however, researches are scarce on the effect of combined chronic administration of tramadol and Codeine on memory (Exploratory learning behaviour).

Exploratory learning is memory acquired through exploring environments. This notion of learning is based upon the idea that learning patterns can be helpfully transferred to dissimilar situations through meta-reflection. The approach of exploratory learning process acknowledges the cognitive process that helps individuals to use their imagination and creativity to draw out lessons from interactions, as well as extracting meaning from experience which can be a complicated process. In this study, we examined the effect of chronic administration of tramadol and codeine on the exploratory learning behaviour of male Albino rats using a T-Maze. It is well known that animals learn to run for food in a maze at a faster rate if they have had previous experience in the environment. This 
phenomenon, generally described as latent learning [47], may offer the possibility to dissociate the effects of drug treatment on learning ability from its effects on performance. By treating an animal with a drug during pre-exposure to the maze, it is possible to study the consequence of the treatment on the ability of the animals to learn a maze at a later time.

The findings of this study showed that $20 \mathrm{mg} / \mathrm{kg}$ single dose of tramadol administered to the tramadol group increased the time the male rats used to explore the maze compared to the control group. The male rats in the control were faster in exploring the maze and getting to the arm where the food was located compared to the male rats in the tramadol group. This is in line with the findings of similar studies. In a study, [48], discovered that treatment of rats with tramadol resulted in an inability of the rats to remember the location of the hidden platform in probe test of Morris Water Maze (MWM).

The effects of neurotoxicity of tramadol have been proven and continuous administration of tramadol has been shown to result in a weight loss of rats' brain [49]. Findings from some recent studies using rodent models have shown that tramadol administration can impair memory functions by activation of $\mu$-opioid receptors [35, 48]. Several studies have also indicated that chronic administration of tramadol can cause histological abnormalities such as increasing apoptosis in rat cerebral cortex which is associated with oxidative stress [50], induce seizures [51], lead to increased oxidative stress in various tissues such as the brain [52] and lead to decrease in the expression of some genes in the hippocampus [53]. The limbic system which is one of the most important areas of the brain because of its role in learning and spatial memory is part of the hippocampus $[54,55,56]$ and the hippocampus is very vulnerable to oxidative stress due to its high metabolic activity $[54,55]$. There is strong evidence from research findings linking tramadol to the increase in the release and turnover of dopamine and serotonin after occasional administration but these neurotransmitters can be depleted through chronic administration of tramadol $[57,6])$. This can explain why tramadol administration decreased memory of the exposed rats following chronic administration of tramadol.

The result from this study shows that male rats exposed to $8 \mathrm{mg} / \mathrm{kg}$ single dose of codeine were slower in exploring the maze compared to the control group. The male rats in the codeine group took more time to explore the maze compared to the control group. In a related study using a Y-Maze task, it was reported that acquisition of spatial recognition memory was impaired after chronic administration of morphine [58]. In another study, it was reported that dependent mice showed cognitive dysfunctions 14 hours after discontinuation of morphine treatment by spending more time to explore the objects in an object recognition task [59].

Studies have shown that abuse of opiate drugs such as codeine correlates with long-lasting cognitive deficits in humans $[60,61,62,63]$. Abusers of opiates like codeine (morphine), heroin, and methadone show impairments in episodic memory [62], visual memory, verbal memory, information processing, problem-solving (60), word fluency and attention [61], and spatial tactile and verbal memory [63]. According to [63], opiate abuse-related cognitive decline may be linked to comprised frontal lobe functions while other studies examining exposure of the drugs on hippocampus morphology and hippocampus-dependent learning and memory suggest that the observed cognitive deficits may be due to altered hippocampal functions. Several studies have indicated that opiate drugs inhibit adult neurogenesis in the hippocampus [64] disrupt spatial memory retention in Morris water maze [65] and Y-maze [66], radial arm maze and Y-maze [67], which are hippocampusdependent tasks [68]. These findings show that both acute and chronic opiate drugs administration results in deficits in hippocampus-dependent learning and memory.

The interaction effect of combined administration of tramadol and codeine as shown in the results presented in Table 2 shows that male rats exposed to codeine alone were slower in exploring the maze $(X=176.64)$ compared to combined codeine and tramadol $(X=168.13)$, compared to tramadol alone $(X=131.10)$ and control (92.48). Male Albino rats in the codeine group took more time in exploring the maze than the combined codeine and tramadol group. This finding did not agree with the hypothesis. It was hypothesized that combined administration of codeine and tramadol will affect exploratory learning in the male Albino rats more than a single administration of either codeine or tramadol. The observed effects may be attributed to the pharmacodynamics of codeine. Codeine is a naturally occurring phenanthrene alkaloid and opioid agonist with analgesic, antidiarrheal and antitussive activities. Codeine mimics the actions of endogenous opioids by binding to the opioid receptors at many sites within the central nervous system (CNS). Stimulation of mu-subtype opioid receptors results in a decrease in the release of nociceptive neurotransmitters such as substance P, GABA, dopamine, acetylcholine and noradrenaline; also, the codeine metabolite morphine induces opening of G-protein-coupled inwardly rectifying potassium (GIRK) channels and blocks the opening of N-type voltage-gated calcium channels, resulting in hyperpolarization and reduced neuronal excitability [69].

\section{Conclusion}

In this study, we showed that the chronic administration of tramadol and codeine in single and combined doses as drugs used for different purposes and particularly abused can impair exploratory learning and memory in rats. These effects can be observed in the single administration of tramadol and codeine as well as in combined administration of tramadol and codeine. The observed effects can be justified according to the properties of tramadol and codeine as opioids. They show inhibitory effects on a wide range of different neurotransmitters and receptors like the NMDA and AMPA in addition to the stimulatory effect on the opioid, GABA, dopamine or serotonin in the brain. 


\section{Acknowledgements}

The authors wish to express gratitude to the Department of Animal Science, University of Ibadan, Nigeria for making their Laboratory available for the study. The Authors wish to state that no funding was received for the study from any agency, the study was self-sponsored by all the authors.

\section{Conflict of Interest}

The Authors hereby declare that there we have no competing interests.

\section{Ethical Approval}

All authors hereby declare that "Principles of laboratory animal care" (National Research Council (2011) GUIDE FOR LABORATORY ANIMALS FOR THE CARE AND USE OF ANIMALS (8ed) were followed, as well as specific national laws where applicable. All experiments have been examined and approved by the appropriate ethics committee"

\section{References}

[1] UNODC. (2017). EXECUTIVE SUMMARY CONCLUSIONS AND POLICY IMPLICATIONS 1 WORLD DRUG REPORT. www.unodc.org/wdr2017

[2] Jentsch, J. D., \& Taylor, J. R. (1999). Impulsivity resulting from frontostriatal dysfunction in drug abuse: Implications for the control of behavior by reward-related stimuli. In Psychopharmacology (Vol. 146, Issue 4, pp. 373-390). https://doi.org/10.1007/PL00005483

[3] Everitt, B. J., \& Robbins, T. W. (2005). Neural systems of reinforcement for drug addiction: From actions to habits to compulsion. In Nature Neuroscience (Vol. 8, Issue 11, pp. 1481-1489). https://doi.org/10.1038/nn1579

[4] Sipahi, A., Satilmis, S., \& Basa, S. (2015). Comparative study in patients with symptomatic internalderangements of the temporomandibular joint: Analgesicoutcomes of arthrocentesis with or without intra-articularmorphine and tramadol. British Journal of Oral and Maxillofacial Surgery, 53 (4), 316-320. https://doi.org/10.1016/j.bjoms.2014.12.018 LK

http://sfx.hul.harvard.edu/sfx local?sid=EMBASE\&issn=153 21940\&id=doi: $10.1016 \% 2 \mathrm{Fj} . \overline{b j o m s} .2014 .12 .018 \&$ atitle $=$ Com parative + study+in+patients+with+symptomatic+internalderan gements + of + the + temporomandibular + joint $\% 3 \mathrm{~A}+$ Analgesicou tcomes + of + arthrocentesis + with + or + without + intraarticularmorphine + and + tramadol\&stitle $=\mathrm{Br} .+\mathrm{J}$. + Oral + Maxillo fac. + Surg. \&title $=$ British + Journal + of + Oral + and + Maxillofacial + Surgery $\&$ volume $=53 \&$ issue $=4 \&$ spage $=316$ \&epage $=320 \&$ au last=Sipahi\&aufirst $=$ A.\&auinit $=$ A.\&auf

[5] Caspani, O., Reitz, M. C., Ceci, A., Kremer, A., \& Treede, R. D. (2014). Tramadol reduces anxiety-related and depressionassociated behaviors presumably induced by pain in the chronic constriction injury model of neuropathic pain in rats. Pharmacology Biochemistry and Behavior, 124, 290-296. https://doi.org/10.1016/j.pbb.2014.06.018

[6] Faron-Górecka, A., Kuśmider, M., Inan, S. Y., Siwanowicz, J.,
\& Dziedzicka-Wasylewska, M. (2004). Effects of tramadol on $\alpha 2$-adrenergic receptors in the rat brain. Brain Research, 1016 (2), 263-267. https://doi.org/10.1016/j.brainres.2004.05.026

[7] Gopalraju, P., Lalitha, R. M., Prasad, K., \& Ranganath, K. (2014). Comparative study of intravenous Tramadol versus Ketorolac for preventing postoperative pain after third molar surgery - A prospective randomized study. Journal of CranioMaxillofacial Surgery, 42 (5), 629-633. https://doi.org/10.1016/j.jcms.2013.09.004

[8] Lofwall, M. R., Babalonis, S., Nuzzo, P. A., Siegel, A., Campbell, C., \& Walsh, S. L. (2013). Efficacy of extendedrelease tramadol for treatment of prescription opioid withdrawal: A two-phase randomized controlled trial *. Drug Alcohol Depend, 133 (1), 188-197. https://doi.org/10.1016/j.drugalcdep.2013.05.010

[9] Fawzi, M. M. (2011). Some medicolegal aspects concerning tramadol abuse: The new Middle East youth plague 2010. An Egyptian overview | Elsevier Enhanced Reader. Egyptian Journal of Forensic Sciences, 99-102. https://reader.elsevier.com/reader/sd/pii/S2090536X1100030X ?token=E929716E3BE86D1F0BF597C94413DA2B670EB6A DE340FBD7474ADBA8C0C1369BACA0331895AF3F0ECD 7C043277DA7C1C

[10] Seifi, M., Hassanpour Moghadam, M., Hadizadeh, F., AliAsgari, S., Aboli, J., \& Mohajeri, S. A. (2014). Preparation and study of tramadol imprinted micro-and nanoparticles by precipitation polymerization: Microwave irradiation and conventional heating method. International Journal of Pharmaceutics, 471 (1-2), 37-44. https://doi.org/10.1016/j.ijpharm.2014.04.071

[11] (WHO), W. H. O. (2017). WHO Expert Committee on Drug Dependence Thirty-ninth report. http://www.

[12] Derry, S., Karlin, S. M., \& Moore, R. A. (2013). Single dose oral ibuprofen plus codeine for acute postoperative pain in adults. In R. A. Moore (Ed.), Cochrane Database of Systematic Reviews (Vol. 2013, Issue 3). John Wiley and Sons Ltd. https://doi.org/10.1002/14651858.CD010107.pub2

[13] Nielsen, S., \& Van Hout, M. C. (2017). Over-the-Counter Codeine-from Therapeutic Use to Dependence, and the Grey Areas in Between. Current Topics in Behavioral Neurosciences, 34, 59-75. https://doi.org/10.1007/7854_2015_422

[14] Cooper, R. (2011). 'Respectable Addiction'-A qualitative study of over the counter medicine abuse in the UK.

[15] Cooper, R. J. (2013). Over-the-counter medicine abuse-a review of the literature. Journal of Substance Use, 18 (2), 82107. https://doi.org/10.3109/14659891.2011.615002

[16] Nations, U., \& Narcotics Control Board, I. (2012). 2011 INTERNATIONAL NARCOTICS CONTROL BOARD Report EMBARGO CAUTION UNITED NATIONS. www.incb.org

[17] Robinson, G. M., Robinson, S. McCarthy, P., \& Cameron, C. (2010). Misuse of over-the counter codeine.containing analgesics: Dependence and and other adverse effects. New Medical Journal, 123 (1317)

[18] Washington Post (2018) Nigeria's ban on codeine cough syrups could spur Black Market ifDemand not addressed. The Henry J. Kaiser FamilyFoundation. https;//www.kff.org/newssummary/nigerians-ban-on-codeine-cough-syrup.could-spurblack-market-if-demand-not-addressed/ 
[19] Kelley, A. E. (2004). Memory and addiction: Shared neural circuitry and molecular mechanisms. In Neuron (Vol. 44, Issue $1, \quad$ pp. 161-179). Cell Press. https://doi.org/10.1016/j.neuron.2004.09.016

[20] Schultz, W. (2010). Open Access REVIEW BioMed Central Dopamine signals for reward value and risk: basic and recent data. https://doi.org/10.1186/1744-9081-6-24

[21] Jay, T. M. (2003). Dopamine: A potential substrate for synaptic plasticity and memory mechanisms. In Progress in Neurobiology (Vol. 69, Issue 6, pp. 375-390). Elsevier Ltd. https://doi.org/10.1016/S0301-0082(03)00085-6

[22] Kalivas, P. (2004). Glutamate systems in cocaine addiction. Current Opinion in Pharmacology, 4 (1), 23-29. https://doi.org/10.1016/j.coph.2003.11.002

[23] Abdolmohamadi, K., Ahmadi, E., Ghadiri, F., Abadi, S., Mohammadzadeh, A., \& Yousefzadeh, B. (2019). Downloaded from frooyesh.ir at 19:21 +0430 on Thursday (Vol. 8, Issue 5).

[24] Stefani, M. R., Groth, K., \& Moghaddam, B. (2003). Glutamate receptors in the rat medial prefrontal cortex regulate set-shifting ability. Behavioral Neuroscience, 117 (4), 728-737. https://doi.org/10.1037/0735-7044.117.4.728

[25] Hosseini-Sharifabad, Ali, Ghahremani, M. H., Sabzevari, O., Naghdi, N., Abdollahi, M., Beyer, C., Bollen, E., Prickaerts, J., Roghani, A., \& Sharifzadeh, M. (2012). Effects of protein kinase $\mathrm{A}$ and $\mathrm{G}$ inhibitors on hippocampal cholinergic markers expressions in rolipram- and sildenafil-induced spatial memory improvement. Pharmacology Biochemistry and Behavior, 101 (3), 311-319. https://doi.org/10.1016/j.pbb.2012.01.017

[26] Sardari, M., Rezayof, A., Khodagholi, F., \& Zarrindast, M. R. (2014). Basolateral amygdala GABA-A receptors mediate stress-induced memory retrieval impairment in rats. International Journal of Neuropsychopharmacology, 17 (4), 603-612. https://doi.org/10.1017/S1461145713001363

[27] Makkar, S. R., Zhang, S. Q., \& Cranney, J. (2010). Behavioral and neural analysis of GABA in the acquisition, consolidation, reconsolidation, and extinction of fear memory. In Neuropsychopharmacology (Vol. 35, Issue 8, pp. 1625-1652). Nature Publishing Group. https://doi.org/10.1038/npp.2010.53

[28] Hritcu, L., Clicinschi, M., \& Nabeshima, T. (2007). Brain serotonin depletion impairs short-term memory, but not longterm memory in rats. Physiology and Behavior, 91 (5), 652657. https://doi.org/10.1016/j.physbeh.2007.03.028

[29] Chavant, F., Favrelière, S., Lafay-Chebassier, C., Plazanet, C., \& Pérault-Pochat, M. C. (2011). Memory disorders associated with consumption of drugs: Updating through a case/noncase study in the French PharmacoVigilance Database. British Journal of Clinical Pharmacology, 72 (6), 898-904. https://doi.org/10.1111/j.1365-2125.2011.04009.x

[30] Abdel-Ghany, R., Nabil, M., Abdel-Aal, M., \& Barakat, W. (2015). Nalbuphine could decrease the rewarding effect induced by tramadol in mice while enhancing its antinociceptive activity. European Journal of Pharmacology, 758, 11-15. https://doi.org/10.1016/j.ejphar.2015.03.062

[31] Spain, J. W., \& Newsom, G. C. (1991a). Chronic opioids impair acquisition of both radial maze and Y-maze choice escape. Psychopharmacology, 105 (1), 101-106. https://doi.org/10.1007/BF02316870

[32] Jesse, C. R., Bortolatto, C. F., Savegnago, L., Rocha, J. B. T., \& Nogueira, C. W. (2008). Involvement of 1-arginine-nitric oxide-cyclic guanosine monophosphate pathway in the antidepressant-like effect of tramadol in the rat forced swimming test. Progress in Neuro-Psychopharmacology and Biological Psychiatry, 32 (8), 1838-1843. https://doi.org/10.1016/j.pnpbp.2008.08.010

[33] Nava-Mesa, M. O., Lamprea, M. R., \& Múnera, A. (2013). Divergent short- and long-term effects of acute stress in object recognition memory are mediated by endogenous opioid system activation. Neurobiology of Learning and Memory, 106, 185-192. https://doi.org/10.1016/j.nlm.2013.09.002

[34] Ng, K. F. J., Yuen, T. S. T., \& Ng, V. M. W. (2006). A comparison of postoperative cognitive function and pain relief with fentanyl or tramadol patient-controlled analgesia. Journal of Clinical Anesthesia, 18 (3), 205-210. https://doi.org/10.1016/j.jclinane.2005.08.004

[35] Hosseini-Sharifabad, A, Rabban, S., Sharifzadeh, M., \& Bagheri, N. (2016). Acute and chronic tramadol administration impair spatial memory in rat. Research in Pharmaceutical Sciences, 11 (1), 49-57.

[36] Hadad, S., \& Assistant, M. (2018). Attention and Memory in Tramadol Addiction. In SOHAG MEDICAL JOURNAL (Vol. 22, Issue 3). www.pdffactory.com

[37] National Research Council (2011) GUIDE FOR LABORATORY ANIMALS FOR THE CARE AND USE OF ANIMALS. Eight Edition Committee for the Update of the Guide for the Care and Use of Laboratory Animals. Institute for LaboratoryAnimal Research Division on Earth animal studies. htpp://www.nap.edu

[38] Uwadiegwu Achukwu, P., Terry Omorodion, N., Tosan, E., aloh, H. E., Charles, E., \& Ome, O. (2019). Codeine and its Histopathological Effect on Brain of Albino Rats: An Experimental Study.

[39] Lee, E. Y., Lee, E. B., Park, B. J., Lee, C. K., Yoo, B., Lim, M. K., Shim, S. C., Sheen, D. H., Seo, Y., Ah Kim, H., Baek, H. J., \& Song, Y. W. (2006). Tramadol 37.5-mg/acetaminophen $325-\mathrm{mg}$ combination tablets added to regular therapy for rheumatoid arthritis pain: A 1-Week, randomized, doubleblind, placebo-controlled trial. Clinical Therapeutics, 28 (12), 2052-2060. https://doi.org/10.1016/j.clinthera.2006.12.019

[40] Vaseghi, G., Rabbani, M., \& Hajhashemi, V. (2013). The effect of AM281, a cannabinoid antagonist, on memory performance during spontaneous morphine withdrawal in mice. Research in Pharmaceutical Sciences, 8 (1), 59.

[41] Benini, F., \& Barbi, E. (2014). Doing without codeine: why and what are the alternatives? https://doi.org/10.1186/18247288-40-16.

[42] Xie, R., \& Hammarlund-Udenaes, M. (1998). Blood-brain barrier equilibration of codeine in rats studied with microdialysis. Pharmaceutical Research, 15 (4), 570-575. https://doi.org/10.1023/A:1011929910782

[43] Hau, V. S., Huber, J. D., Campos, C. R., Davis, R. T., \& Davis, T. P. (2004). Effect of $\lambda$-carrageenan-induced inflammatory pain on brain uptake of codeine and antinociception. Brain Research, 1018 (2), 257-264. https://doi.org/10.1016/j.brainres.2004.05.081

[44] Birthelmer, A., Stemmelin, J., Jackisch, R., \& Cassel, J. C. (2003). Presynaptic modulation of acetylcholine, noradrenaline, and serotonin release in the hippocampus of aged rats with various levels of memory impairments. Brain Research Bulletin, 60 (3), 283-296. https://doi.org/10.1016/S0361-9230(03)00042-X 
[45] Dubrovina, N. I., \& Ilyutchenok, R. Y. (1996). Dopamine and opioid regulation of the memory retrieval recovery in mice. Behavioural Brain Research, 79 (1-2), 23-29. https://doi.org/10.1016/0166-4328(95)00258-8

[46] Ghamati, L., Hajali, V., Sheibani, V., Esmaeilpour, K., Sepehri, G., \& Shojaee, M. (2014). Single and repeated ultrarapid detoxification prevents cognitive impairment in morphine addicted rats: a privilege for single detoxification. Addiction \& Health, 6 (1-2), 54-64. http://www.ncbi.nlm.nih.gov/pubmed/25140218

[47] Mackintosh, N. J. (1975). A theory of attention: Variations in the associability of stimuli with reinforcement. Psychological Review, 82 (4), 276-298. https://doi.org/10.1037/h0076778

[48] Baghishani, F., Mohammadipour, A., Hosseinzadeh, H., Hosseini, M., \& Ebrahimzadeh-bideskan, A. (2018). The effects of tramadol administration on hippocampal cell apoptosis, learning and memory in adult rats and neuroprotective effects of crocin. Metabolic Brain Disease, 33 (3), 907-916. https://doi.org/10.1007/s11011-018-0194-6

[49] Zhuo, H. Q., Huang, L., Huang, H. Q., \& Cai, Z. (2012). Effects of chronic tramadol exposure on the zebrafish brain: A proteomic study. Journal of Proteomics, 75 (11), 3351-3364. https://doi.org/10.1016/j.jprot.2012.03.038

[50] Ghoneim, F. M., Khalaf, H. A., Elsamanoudy, A. Z., \& Helaly, A. N. (2014). Effect of chronic usage of tramadol on motor cerebral cortex and testicular tissues of adult male albino rats and the effect of its withdrawal: Histological, immunohistochemical and biochemical study. International Journal of Clinical and Experimental Pathology, 7 (11), 7323 7341 .

[51] Boostani, R., \& Derakhshan, S. (2012). Tramadol induced seizure: A 3-year study. Caspian Journal of Internal Medicine, 3 (3), 484-487.

[52] Hussein, S. A., Samir,;, Latif, A., Aal, A., \& Ismail, H. K. (2017). Neurodegeneration and oxidative stress induced by tramadol administration in male rats: The effect of its withdrawal. http://www.bvmj.bu.edu.eg

[53] Candeletti, S., Lopetuso, G., Cannarsa, R., Cavina, C., \& Romualdi, P. (2006). Effects of prolonged treatment with the opiate tramadol on prodynorphin gene expression in rat CNS. Journal of Molecular Neuroscience, 30 (3), 341-347. https://doi.org/10.1385/JMN:30:3:341

[54] Kim, E. J., Pellman, B., \& Kim, J. J. (2015). Stress effects on the hippocampus: A critical review. In Learning and Memory (Vol. 22, Issue 9, pp. 411-416). Cold Spring Harbor Laboratory Press. https://doi.org/10.1101/lm.037291.114

[55] Chieffi, S., Messina, G., Villano, I., Messina, A., Esposito, M., Monda, V., Valenzano, A., Moscatelli, F., Esposito, T., Carotenuto, M., Viggiano, A., Cibelli, G., \& Monda, M. (2017). Exercise influence on hippocampal function: Possible involvement of orexin-a. Frontiers in Physiology, 8, 85. https://doi.org/10.3389/fphys.2017.00085

[56] Rajabian, A., Hosseini, A., Hosseini, M., \& Sadeghnia, H. R. (2019). A review of potential efficacy of saffron (Crocus sativus L.) in cognitive dysfunction and seizures. In Preventive Nutrition and Food Science (Vol. 24, Issue 4, pp. 363-372). Korean Society of Food Science and Nutrition. https://doi.org/10.3746/pnf.2019.24.4.363
[57] Zarrindast, M. R., Hoghooghi, V., \& Rezayof, A. (2008). Inhibition of morphine-induced amnesia in morphinesensitized mice: Involvement of dorsal hippocampal GABAergic receptors. Neuropharmacology, 54 (3), 569-576. https://doi.org/10.1016/j.neuropharm.2007.11.004

[58] Kouwenberg, A.-L., Martin, G. M., Skinner, D. M., Thorpe, C M., \& Walsh, C. J. (2012). Spontaneous Object Recognition in Animals: A Test of Episodic Memory. www.intechopen.com

[59] Rabbani, M., Hajhashemi, V., \& Mesripour, A. (2009). Increase in brain corticosterone concentration and recognition memory impairment following morphine withdrawal in mice. Stress, $12 \quad$ (5), 451-456. https://doi.org/10.1080/10253890802659612

[60] Darke, S., Sims, J., McDonald, S., \& Wickes, W. (2000). Cognitive impairment among methadone maintenance patients. Addiction, 95 (5), 687-695. https://doi.org/10.1046/j.13600443.2000.9556874.x

[61] Davis, P. E., Liddiard, H., \& McMillan, T. M. (2002). Neuropsychological deficits and opiate abuse. Drug and Alcohol Dependence, $67 \quad$ (1), 105-108. https://doi.org/10.1016/S0376-8716(02)00012-1

[62] Curran, H. V., Kleckham, J., Bearn, J., Strang, J., \& Wanigaratne, S. (2001). Effects of methadone on cognition, mood and craving in detoxifying opiate addicts: A doseresponse study. Psychopharmacology, 154 (2), 153-160. https://doi.org/10.1007/s002130000628

[63] Ornstein, T. J., Iddon, J. L., Baldacchino, A. M., Sahakian, B. J., London, M., Everitt, B. J., \& Robbins, T. W. (2000). Profiles of cognitive dysfunction in chronic amphetamine and heroin abusers. Neuropsychopharmacology, 23 (2), 113-126. https://doi.org/10.1016/S0893-133X(00)00097-X

[64] Eisch, A. J., Barrot, M., Schad, C. A., Self, D. W., \& Nestler, E. J. (2000). Opiates inhibit neurogenesis in the adult rat hippocampus. www.pnas.orgcgidoi10.1073pnas. 120552597

[65] Farahmandfar, M., Karimian, S. M., Naghdi, N., Zarrindast, M. R., \& Kadivar, M. (2010). Morphine-induced impairment of spatial memory acquisition reversed by morphine sensitization in rats. Behavioural Brain Research, 211 (2), 156-163. https://doi.org/10.1016/j.bbr.2010.03.013

[66] Ma, M. X., Chen, Y. M., He, J., Zeng, T., \& Wang, J. H. (2007). Effects of morphine and its withdrawal on Y-maze spatial recognition memory in mice. Neuroscience, 147 (4), $1059-1065$.

https://doi.org/10.1016/j.neuroscience.2007.05.020

[67] Spain, J. W., \& Newsom, G. C. (1991b). Chronic opioids impair acquisition of both radial maze and Y-maze choice escape. Psychopharmacology, 105 (1), 101-106. https://doi.org/10.1007/BF02316870

[68] Retailleau, A., Dejean, C., Fourneaux, B., Leinekugel, X., \& Boraud, T. (2013). Why am I lost without dopamine? Effects of 6-OHDA lesion on the encoding of reward and decision process in CA3. Neurobiology of Disease, 59, 151-164. https://doi.org/10.1016/j.nbd.2013.07.014

[69] Papich, M. G. (2016). Codeine. In Saunders Handbook of Veterinary Drugs (pp. 183-184). Elsevier. https://doi.org/10.1016/B978-0-323-24485-5.00175-3 